\title{
PROBING THE GOLD BINDING SITE IN SERUM ALBUMIN
}

\author{
Rodney E. Sue, Peter J. Sadler and Alan Tucker \\ Department of Chemistry, Birkbeck College, University of London, Gordon House, \\ 29 Gordon Square, London WC1H OPP, UK
}

The antiarthritic drug, auranofin ("Ridaura") is an orally-active antiarthritic drug containing linear $A u(I)$. The gold is co-ordinated by triethylphosphine and the sulfur of tetraacetyl- $\beta-D-1-$ thioglucose (HSATg). Deacetylation occurs during absorption and then the thioglucose is displaced via ligand displacement reactions. Over $80 \%$ of the gold in the blood is carried by serum albumin, ${ }^{1}$ a $66 \mathrm{kDa}$ single-chain protein with high helical content and three strucurally similar domains. ${ }^{2}$

Previous studies have shown that the gold binds to cysteine-34 in domain I of albumin, which has an unusually low $\mathrm{pKa}_{\mathrm{a}}(<5), 3,4$

We have now synthesised a number of potentially antiarthritic gold complexes with a variety of substitution patterns, including the chiral phosphine complex [PhMeEtPAuCl], I, and studied their binding to serum albumin by ${ }^{1} \mathrm{H}$ and ${ }^{31} \mathrm{P}$ NMR spectroscopy. The structural changes induced in albumin by these gold complexes, and comparative reactions with other thiols will be discussed.

We thank the Wellcome Trust, MRC and Wolfson Foundation for support.

\section{References}

1. A.E. Finkelstein, D.T. Walz, V. Batista, M. Mizraji, F. Toisman and A. Misher, Ann. Rheum. Dis., 1976, 35, 251.

2. D.C. Carter and X.-M. He, Nature, 1992, 358, 209.

3. O.M. Ni Dhubhghaill, P.J. Sadler and A. Tucker, J. Am. Chem. Soc., 1992, 114, 1118.

4. C.F. Shaw III, Comments Inorg. Chem., 1989, $8,233$. 